\title{
Thoughts on Perfecting Insurance System of Unemployed Military Spouses Who Followed the Army
}

\author{
Pengcheng Xiao ${ }^{1, a, *}$ \\ ${ }^{1}$ Complete Project Research, Logistics University of Chinese People’s Armed Police Force, Tianjin, China \\ a1441093494@qq.com
}

Keywords: Unemployed Military Spouse Insurance, Perfecting Insurance System, Thoughts.

\begin{abstract}
It is an important part of the military insurance system to play an important role in dispersing the risk of spouses' joint ventures and relieving the soldiers from worries. This paper puts forward the suggestions of rationalization for the existing problems of the spouses 'insurance system of the unarmed military personnel, which is of great significance to further strengthen the work of the spouses' insurance of the unarmed military personnel and enhance the combat effectiveness of the army.
\end{abstract}

\section{Introduction}

July 1, 2012 promulgated and implemented the "People's Republic of China Army Insurance Law", the military spouse insurance as one of the four categories of insurance insurance, fully affirmed the military spouse insurance in military insurance status. In order to promote its healthy development, the Army Military Insurance Commission issued "on the further strengthening of military insurance theory research notice", will improve the military spouse insurance system as a research focus. According to the social insurance to improve the sound situation, combined with the actual social insurance system in various regions, research and demonstration and further adjust the military spouse insurance system. This series of initiatives reflect the military spouse insurance system in the military insurance system system increasingly important position.

\section{The Content of the Insurance System of Unemployed Military Spouses Who Followed the Army}

The military spouse insurance system is different from the single insurance guarantee for the active military personnel. It is a kind of security system which includes multiple insurance types. The main contents include the basic living allowance, the old-age insurance and the medical insurance. Among them, the old-age insurance and medical insurance are only established personal account.

\subsection{Basic Living Allowance}

For the distribution of basic living allowance of the insurance object, according to its military forces different geographical location, the degree of difficulty is different, different types of alpine islands, will receive the standard of subsidies is divided into three grades, the standard step by step. According to the annual budget approved by the Central Military Commission, the Military Affairs Department Political Work Department and the Logistics Support Department jointly issued a notice to determine that from January 1, 2016, the focus on the coastal defense, high altitude Gobi and other resident conditions particularly difficult, lack of social support troops Tilt, play the incentive role of policy system. Among them, in the country to determine the first and second class of arduous areas and the military to determine the three types of islands, as well as the general area of the military, the spouse of the army during the employment of basic living allowance from 900 yuan adjusted to 1,100 yuan; , Four types of hardships and remote areas and the army to determine the second class islands and the implementation of the second class of Tibet's military, the spouse of the army during the employment of basic living allowance from 1,100 yuan adjusted to 1,400 yuan 
in the country to determine the five or six hard Regions and the army to determine the special, a class of islands and Tibet to implement three or four categories of military, the spouse with the army during the employment of basic living allowance from 1,300 yuan adjusted to 1,700 yuan.

\subsection{Old-age Insurance}

Military spouse insurance system in the payment base to establish the standard, the specific value of the payment base, the proportion of payment has made the provisions of the military spouse with the army did not employment during the pension insurance, according to the provisions of the contribution rate of $8 \%$ of the contribution, by the military unit Deducted payment, all credited to the old personal insurance account. The base of pension insurance contribution is determined by the proportion of $60 \%$ of the monthly average monthly wage of urban workers in the previous year. The current contribution base is 3,000 yuan. When the old-age insurance relationship is transferred to the place, the state shall grant the subsidy in accordance with the sum of $12 \%$ of the actual contribution base of the individual after 1 January 1998, and transfer to the local social security agency with the total storage amount of the individual account.

\subsection{Medical Insurance}

The medical insurance account is paid by the individual and is subsidized by the government. The payment base for medical insurance is the full amount of the basic living allowance of the spouse, the proportion of personal contribution is $1 \%$, and then the government subsidizes the same amount, all credited to the medical insurance personal account.

\section{Problems of the Insurance System of Unemployed Military Spouses Who Followed the Army}

\subsection{The Level of the Insurance Treatment is low}

There is a lack of fairness in the spousal insurance of non-employed military personnel, and the system curing leads to the low level of treatment. First, the basic living allowance to solidify the absolute amount to determine the form of subsidy standards unreasonable, did not form a regular growth mechanism or with the local urban workers income level linked; second, the medical insurance account accumulation standards and basic living allowance Relevant, the amount of subsidies to the amount of medical insurance caused by the accumulation of low levels of health insurance. Third, the insurance base of solidification, the lack of corresponding adjustment mechanism, growth mechanism, there is no clear rules and regulations when the adjustment, when the increase.

\subsection{Transference between Army and Civilian of the Insurance is Difficult}

At present, the military is not employed with the spouse's basic living allowance, pension insurance, medical insurance by the military finance department unified management. When the military out of active service, the spouse's insurance relationship with the transfer to the placement of social insurance institutions. The problems in the transfer of military spouse insurance are: first, there is a problem of discontinuous monthly payment. Second, the policy interpretation of the existence of bias, resulting in more than one account situation. In the process of transfer, because the troops into only two risks, with the families of the basic life subsidies and social insurance, in the local and flexible employment in the form of an account, or not existing accounts transferred to the army, the formation of One more account phenomenon. Third, the system matches the problem. Local social security system upgrade, the military spouse's insurance account transfer, and the new system does not match, affecting the military and the convergence between.

\subsection{Coverage of the insurance is Poor}

Compared with the local social insurance, the existing military spouse insurance insurance less, the scope of protection is narrow, local social insurance in addition to basic pension and medical insurance, but also set up unemployment insurance, industrial injury insurance and maternity 
insurance. Part of the local enterprises also insured workers for the enterprise workers to supplement the old-age insurance and supplementary medical insurance.

\section{Treatments of Perfecting the Insurance System of Unemployed Military Spouses Who Followed the Army}

\subsection{Improving the level of the Insurance System of Unemployed Military Spouses Who Followed the Army}

First, to break the current fixed insurance insurance base, the insurance payment base of the upper and lower limits of the proportion of economic development and linked to the military family members to give appropriate choice of rights. One side to set a reasonable with a good economic adaptability of the payment base, the specific payment ratio should be military insurance management agencies together with the social security management agencies, through adequate research and demonstration to determine. On the other hand set different grades of standards for military spouses to choose. Although the surface of the insured military spouse is no income, but the monthly premiums are deducted from the basic living allowance, and with the military salary of the continuous adjustment of the military family security contributions have been greatly improved, With the choice of a variety of grades of economic capacity. Because the insurance treatment, especially pension insurance, and premium payment level is directly related. In order to protect the life of old age, the military family has the intention to raise the premium. Therefore, the system should be developed when the insured according to their income level and pension expectations, from different grades of payment base to choose the right to give the military family members appropriate choice. Second, timely and appropriate, adjust the payment standard. Each year according to the national and local statistical income information, timely adjustment of the base and the proportion of payment, only the timely adjustment of the flexibility of the system can be implemented. While timely adjustment can also avoid the intermittent adjustment caused by the base and economic development out of touch with the problem. Should be in accordance with the national social security system in accordance with the annual basis to determine the payment base of the regular payment base adjustment, the establishment of regular adjustment mechanism, to be able to follow, Third, a reasonable increase in basic living allowance. Economic development at the same time, people's living standards have been rising. The military for the work of many sacrifice, the military choose the army may give up their original work; the other as a result of the military as a result of the task, the resident often face adjustment, to the military family members to find a job to bring some difficulties, a large part of the military family life The income of the soldiers to maintain; Therefore, should be in accordance with the principle of moderation, a reasonable increase in basic living allowance, improve the level of protection of military spouses.

\subsection{Optimize the Connection between Military and Civilian Insurance}

Military spouse's pension and medical insurance is also the protection of the social population, do not consider the payment of living subsidies, military spouse insurance and local social insurance in the operational processes, methods have a high degree of similarity. Now the military gap is fundamentally speaking, is due to the implementation of the military spouse insurance coverage of the differences caused by military norms. Can be "military system" military spouse insurance module military design. Through the integrated design of the operating platform, to achieve operational processes, methods of unity, to achieve the underlying data seamless link. This can solve the problem that the interface information is not unified and the system parameters do not match. To solve the information because of inconsistent and repeated rework caused by the human, material and financial resources of the waste and the transfer of military spouse insurance transfer delays. In addition, the realization of institutional changes in the integration. As the insurance system is integrated in the operating system, when the social security system changes, such as fund collection methods, payment ratio changes, the military system integration makes the military 
spouse insurance system changes in time, to avoid the military spouse insurance system adjustment Of the hysteresis caused by the military to connect the cracks.

\subsection{Enlarge the Coverage of the Insurance System}

In the current endowment insurance and medical insurance on the basis of a sound army of non-employed military spouse insurance insurance. The establishment of unemployment insurance personal accounts, timely establishment of maternity insurance and casualty insurance, and local social insurance to match. The current spans of the unarmed military spouses' insurance system is designed to solve the problem of social insurance during the period of non-employment of military spouses. However, since the spouses of military personnel will eventually take their social insurance from the local social security institutions with the military officers withdraw from their active service or realize their employment. From the current situation , The implementation of social insurance throughout the situation despite the differences, but basically set the old-age insurance, medical insurance, unemployment insurance, industrial injury insurance and maternity insurance, the insurance required by the individual or unit to pay, and then included in the individual Account. Especially the first three kinds of insurance, because the length of their payment time and personal benefits directly related to, therefore, with the spouses during the employment of social insurance should be based on the existing pension and medical insurance as soon as possible to establish unemployment insurance personal accounts to protect the spouse The legitimate interests.

\section{References}

[1] Jinlin Huang. Discussion on the socialization of social insurance management of the unemployed military spouses when following the army[J]. Smart City,2016,2(06):122-123.

[2] Wensheng Yu, Enming Cha, Guojun Wu.The problems and Countermeasures of the social insurance system of the unemployed military spouses when following the army[J]. The study of military economy,2005,(07):53-54.

[3] Anonymous. VA Reduces Monthly Family SGLI Premiums[J]. National Guard,2010,64(6).

[4] Anonymous. Armed Forces Insurance; AFI Sponsors Military Spouse Magazine's Military Spouse of the Year Award[J]. Defense \&amp; Aerospace Week,2011.

[5] Alexander P. Cole, Wei Jiang, Stuart R. Lipsitz, Peter A. Learn, Maxine Sun, Toni K. Choueiri, Paul L. Nguyen, Adam S. Kibel, Mani Menon, Jesse D. Sammon, Tracey Koehlmoos, Adil Haider, Quoc-Dien Trinh. The Use of Prostate Specific Antigen Screening in Purchased versus Direct Care Settings: Data from the TRICARE® Military Database[J]. The Journal of Urology,2017. 